\title{
Blunted Hypercapnic Respiratory Drive Response in Subjects With Late-Onset Pompe Disease
}

\author{
Eduardo L De Vito MD, Sergio G Monteiro PT, and Patricia K Aruj MD
}

\begin{abstract}
BACKGROUND: Patients with late-onset Pompe disease develop progressive hypercapnic respiratory failure that can be disproportionate to the respiratory muscle compromise and/or thoracic restriction. Although recent studies have reported the presence of a blunted hypercapnic respiratory response in some subjects with neuromuscular disorders and chronic hypercapnia, no study has evaluated the integrity of the respiratory drive in subjects with late-onset Pompe disease. Thus, we endeavor to determine the $\mathrm{CO}_{2}$ rebreathing response in subjects with late-onset Pompe disease. METHODS: Respiratory muscle strength was assessed by measuring the maximum inspiratory pressure, and the maximum expiratory pressure. The maximum inspiratory pressure reflects the strength of the diaphragm and other inspiratory muscles, whereas the maximum expiratory pressure reflects the strength of the abdominal muscles and other expiratory muscles. We studied the hypercapnic drive response (measured as the ratio of the change in airway-occlusion pressure $0.1 \mathrm{~s}$ after the start of inspiration and end-tidal $\mathrm{P}_{\mathrm{CO}_{2}}$ in 13 subjects with late-onset Pompe disease and 51 healthy controls. RESULTS: Overall inspiratory muscle strength was within normal limits or slightly diminished in the late-onset Pompe disease group. Five subjects $(38.5 \%)$ were chronically hypercapnic, and $9(69.2 \%)$ had an increased breath-holding time. Compared with controls, the change in airway-occlusion pressure 0.1 s/change in end-tidal $\mathrm{CO}_{2}$ pressure slope (hypercapnic respiratory drive) was lower in the late-onset Pompe disease group (median 0.050 [interquartile range $0.027-0.118]$ vs 0.183 [0.153-0.233], $P<.001)$. Nine subjects $(69.2 \%)$ had a blunted change in airway-occlusion pressure 0.1 s/change in end-tidal carbon dioxide pressure slope. CONCLUSIONS: Subjects with late-onset Pompe disease had an impaired hypercapnic respiratory drive response. The clinical impact of this phenomenon in this subject subset deserves further investigation. Key words: late-onset Pompe disease; control of breathing; hypercapnic respiratory drive; central chemoreception; hypercapnia; respiratory under responsiveness to hypoxia and hypercapnia. [Respir Care 2016;61(7):930-935. ㅇ 2016 Daedalus Enterprises]
\end{abstract}

\section{Introduction}

Pompe disease, also known as glycogen storage disease type II, is an autosomal recessive inherited disorder, due to a reduced activity of the lysosomal acid $\alpha$-glucosidase. ${ }^{1}$ This enzyme deficiency results in failure of lysosomal glycogen degradation, leading to progressive glycogen ac-

\footnotetext{
The authors are affiliated with the Instituto de Investigaciones Médicas Alfredo Lanari, Universidad de Buenos Aires, Ciudad Autónoma de Buenos Aires, Argentina. Dr De Vito is also affiliated with the Consejo Nacional de Investigaciones Científicas y Técnicas (CONICET), Ciudad Autónoma de Buenos Aires, Argentina.
}

The authors have disclosed no conflicts of interest. cumulation in various tissues. ${ }^{2}$ There are 2 distinct clinical presentations of Pompe disease: a severe infantile one with cardiomyopathy, respiratory distress, and muscle hypotonia and a late-onset form characterized by a progressive myopathy. ${ }^{2}$ Age of onset and phenotype in late-onset Pompe disease can vary greatly, but most typically, patients present with symptoms secondary to skeletal muscle weak-

Correspondence: Eduardo Luis De Vito MD, Instituto de Investigaciones Médicas Alfredo Lanari, Combatientes de Malvinas 3150, 1427 Ciudad Autónoma de Buenos Aires, Argentina. E-mail: eldevito@gmail.com.

DOI: $10.4187 /$ respcare. 03940 
ness, whereas clinical prognosis mainly depends on the degree of respiratory involvement. ${ }^{1}$

Patients with neuromuscular disorders, including patients with late-onset Pompe disease, may present with $\mathrm{CO}_{2}$ retention out of proportion to the degree of respiratory muscle weakness and the alterations of lung mechanics. ${ }^{3,4} \mathrm{In}$ subjects with neuromuscular disorders, some studies have reported a blunted central respiratory drive as the culprit for chronic hypercapnia; however, specifically in subjects with late-onset Pompe disease, no study has evaluated the integrity of the central respiratory drive.

The aim of the present study was to determine the integrity of the central respiratory drive in subjects with late-onset Pompe disease by measuring the occlusion pressure response to $\mathrm{CO}_{2}$ rebreathing, a parameter that is independent of respiratory muscle strength and lung mechanics. $^{5,6}$

\section{Methods}

\section{Population}

We included 13 subjects with late-onset Pompe disease and 51 healthy subjects. We used previously collected data from a control group to find reference values for the technique. Normal subjects who worked or studied at our university medical center participated as healthy controls. The subjects with late-onset Pompe disease were assessed at the pulmonary laboratory of neuromuscular disorders in an out-patient setting. We defined healthy subjects as individuals with no prior pulmonary or cardiac medical history, absence of respiratory or cardiac complaints, normal chest radiographs, and an end-tidal $\mathrm{CO}_{2}\left(\mathrm{P}_{\mathrm{ETCO}_{2}}\right)$ of $\leq 45 \mathrm{~mm} \mathrm{Hg}$. The present study was reviewed and approved by the institutional ethics committee, and informed consent was obtained in all cases from the subjects and healthy controls.

\section{Measurements and Procedures}

Respiratory muscle strength was assessed by measuring the maximum inspiratory pressure $\left(\mathrm{P}_{\mathrm{Imax}}\right)$ and the maximum expiratory pressure $\left(\mathrm{P}_{\mathrm{Emax}}\right)$. The $\mathrm{P}_{\mathrm{Imax}}$ reflects the strength of the diaphragm and other inspiratory muscles, whereas the $\mathrm{P}_{\text {Emax }}$ reflects the strength of the abdominal muscles and other expiratory muscles. These static maximum pressures at the mouth were obtained with a snorkel-like mouthpiece coupled with a unidirectional Hans Rudolph valve connected to a pressure transducer (Validyne MP 45, Validyne Engineering, Northridge, California). Data were recorded in a digital format (MP100 Workstation, Biopac Systems, Goleta, California). For acquisition, the signals were passed through an analog-to-digital conversion board

\section{QUICK LOOK}

\section{Current knowledge}

Several studies have identified a blunted central respiratory drive in subjects with neuromuscular disorders. However, it is not known whether such an anomaly occurs in subjects with late-onset Pompe disease.

\section{What this paper contributes to our knowledge}

In the present study, subjects with late-onset Pompe disease had chronic hypercapnia that appeared disproportionate to the degree of respiratory muscle weakness and mechanical defect. In these subjects, we found a low response to inhaled $\mathrm{CO}_{2}$, which confirmed the presence of a blunted central respiratory drive.

(Biopac Systems) at a $60-\mathrm{Hz}$ sampling rate. The signals from the pressure transducers were filtered with lowpass filters $(\leq 30 \mathrm{~Hz})$. Maximum static pressures were considered normal according to Evans equations. ${ }^{7}$

$\mathrm{S}_{\mathrm{pO}_{2}}$ and $\mathrm{P}_{\mathrm{ETCO}}$ were measured (Oscar Oxy, Datex, Helsinki, Finland). Arterial blood gas samples were obtained from the radial artery while the subject was at rest in the sitting position and breathing room air. Analyses of $\mathrm{P}_{\mathrm{O}_{2}}$ and $\mathrm{P}_{\mathrm{CO}_{2}}$ were made with standard equipment (ABL 800, Radiometer, Copenhagen, Denmark).

Although it appeared not to be a reference with this cut-off value, $\mathrm{P}_{\mathrm{ETCO}}$ is a measure of end-tidal $\mathrm{CO}_{2}$ as an estimate of $\mathrm{P}_{\mathrm{aCO}_{2}} \cdot \mathrm{P}_{\mathrm{ETCO}_{2}} \approx$ alveolar partial pressure of $\mathrm{CO}_{2} \approx \mathrm{P}_{\mathrm{aCO}_{2}}$. In normal conditions, $\mathrm{P}_{\mathrm{ETCO}}$ is a close approximation change by very similar $\mathrm{P}_{\mathrm{aCO}}$. The normal values of $\mathrm{P}_{\mathrm{ETCO}_{2}}$ are around $5 \%$, or $35-37 \mathrm{~mm} \mathrm{Hg}$. According to the 2010-2015 American Heart Association Guidelines for Advanced Cardiovascular Life Support, normal $\mathrm{P}_{\mathrm{ETCO}_{2}}$ in the adult patient should be $35-45 \mathrm{~mm} \mathrm{Hg}{ }^{8}$

In order to measure breath-holding time, following a few sighs, subjects were asked to perform maximum inspiration and then hold respiration for as long as possible. We performed the test twice and registered the highest value. ${ }^{9}$ A prolonged breath-holding time may suggest impaired $\mathrm{CO}_{2}$ chemosensitivity.

\section{$\mathrm{CO}_{2}$ Chemosensitivity Response Test}

This test was performed using the Read re-inhalation technique described by Whitelaw et al. ${ }^{5,6}$ Briefly, subjects sat comfortably on a chair. After determining the baseline occlusion pressure during the first $0.1 \mathrm{~s}$ of inspiration $\left(\mathrm{P}_{0.1}\right)$, the subjects re-inhaled from a rubber bag a progressively increasing mixture of $\mathrm{CO}_{2}\left(7 \% \mathrm{CO}_{2}\right.$, balanced to oxygen) during $4 \mathrm{~min}$ in a closed circuit. Flow at the mouth was 
Table 1. Baseline Demographics and Respiratory Function

\begin{tabular}{|c|c|c|c|}
\hline Characteristics & Pompe Disease Group $(n=13)$ & Control Group $(n=51)$ & $P$ \\
\hline Age, median (IQR) y & $45.0(29.7-58.5)$ & $34.0(28.0-39.7)$ & .57 \\
\hline Age at onset, median (IQR) y & $20.0(15.0-26.2)$ & NA & NA \\
\hline Female sex, $n(\%)$ & $8(61.5 \%)$ & $22(43.1 \%)$ & .19 \\
\hline Weight, median (IQR) kg & $67.0(59.7-79.0)$ & $65.0(60.0-71.7)$ & .57 \\
\hline Height, median (IQR) cm & $1.69(1.55-1.80)$ & $1.69(1.65-1.72)$ & .99 \\
\hline BMI, median (IQR) kg/m² & $23.8(20.9-28.9)$ & $23.2(21.9-24.8)$ & .51 \\
\hline $\mathrm{P}_{\mathrm{ETCO}_{2}}$, median (IQR) mm Hg & $40.4(38.4-46.8)$ & $39.1(37.6-40.2)$ & .09 \\
\hline$\Delta \mathrm{P}_{0.1} / \Delta \mathrm{P}_{\mathrm{CO}_{2}}$, median (IQR) $\mathrm{cm} \mathrm{H}_{2} \mathrm{O} / \mathrm{mm} \mathrm{Hg}$ & $0.050(0.027-0.118)$ & $0.183(0.153-0.233)$ & .001 \\
\hline $\begin{array}{l}\mathrm{IQR}=\text { interquartile range } \\
\mathrm{NA}=\text { not applicable } \\
\mathrm{BMI}=\text { body mass index } \\
\mathrm{P}_{\mathrm{ETCO}_{2}}=\text { end-tidal } \mathrm{P}_{\mathrm{CO}_{2}} \\
\mathrm{P}_{0.1}=\text { occlusion pressure obtained during the first } 0.1 \mathrm{~s} \text { dur } \\
\Delta \mathrm{P}_{0.1} / \Delta \mathrm{P}_{\mathrm{CO}_{2}}=\text { hypercapnic drive response }\end{array}$ & it inspiration (zero flow) & & \\
\hline
\end{tabular}

obtained by means of a pneumotachograph connected to a medium size Hans Rudolph valve.

Both pneumotachograph catheters were connected to a differential pressure transducer, and another catheter was connected to an oxicapnograph that measured $\mathrm{P}_{\mathrm{ETCO}}$ while a fourth catheter was used to measure mouth pressure (MP-45). Consequently, one catheter measured mouth pressure, another measured $\mathrm{P}_{\mathrm{ETCO}_{2}}$, and the remaining 2 catheters were connected to the pneumotachograph for the assessment of pressure differential (flow). All signals were amplified and passed via an analog-digital board to a computer running Acknowledge software (Biopac Systems). Subjects were asked to breath for 4 min while we occluded the silent pneumatic valve during expiration. The pressure obtained during the first $0.1 \mathrm{~s}$ during the subsequent inspiration (zero flow) was the $\mathrm{P}_{0.1}$. After that, we immediately reopened the pneumatic valve and assessed the $\mathrm{P}_{\mathrm{ETCO}_{2}}$ before occlusion.

Two $\mathrm{CO}_{2}$ rebreathing tests were performed on each subject. Each consisted of about 15 occlusions. Each test was visually analyzed, and slope $\mathrm{P}_{0.1} / \mathrm{P}_{\mathrm{CO}_{2}}(\mathrm{~cm} \mathrm{H}$ was obtained. After that, a single slope with all occlusions was obtained. Slope values reported reflect the $\mathrm{CO}_{2}$ chemosensitivity.

\section{Statistical Analysis}

Statistical analysis was performed with the SPSS 12.0 package (SPSS, Chicago, Illinois). Categorical data are presented as frequencies and percentages. After checking for normal distribution with Shapiro-Wilk test, continuous variables were reported as mean $\pm \mathrm{SD}$ or median (interquartile range). Statistical comparison for continuous variables was performed using the Student $t$ test or MannWhitney rank-sum test and Fisher exact test for binary variables. $P$ values $<.05$ were considered significant. Cor-
Table 2. Respiratory Parameters in the Late-Onset Pompe Disease Group

\begin{tabular}{lc}
\hline \multicolumn{1}{c}{ Variables } & \multicolumn{1}{c}{ Values } \\
\hline FVC-seated, mean $\pm \mathrm{SD}, \mathrm{L}$ & $2.84 \pm 0.92$ \\
FVC-seated, mean $\pm \mathrm{SD} \%$ predicted & $69.65 \pm 23.09$ \\
FVC-supine, median (IQR) L & $1.46(1.27-3.37)$ \\
FVC-seated, mean $\pm \mathrm{SD} \%$ predicted* & $51.17 \pm 27.59$ \\
FVC, mean $\pm \mathrm{SD} \%$ fall & $29.95 \pm 18.11$ \\
$\mathrm{P}_{\text {Imax }}$, mean $\pm \mathrm{SD}$ mm Hg & $55.23 \pm 16.45$ \\
$\mathrm{P}_{\text {Imax }}$, mean $\pm \mathrm{SD} \%$ predicted & $60.30 \pm 16.19$ \\
$\mathrm{P}_{\text {Imax }}$, mean $\pm \mathrm{SD} \%$ lower limit of normal range & $111.78 \pm 35.20$ \\
$\mathrm{P}_{\text {Emax }}$, mean $\pm \mathrm{SD}$ mm Hg & $77.70 \pm 21.49$ \\
$\mathrm{P}_{\text {Emax }}$, mean $\pm \mathrm{SD} \%$ predicted & $69.56 \pm 23.78$ \\
$\mathrm{P}_{\text {Emax }}$, mean $\pm \mathrm{SD} \%$ lower limit of normal range & $107.49 \pm 31.06$ \\
Breath-holding time, mean $\pm \mathrm{SD} \mathrm{s}$ & $93.5 \pm 40.3$ \\
& \\
\hline$N=13$. & \\
$* P=.048$ with seated. & \\
$\mathrm{I}_{\mathrm{P}}=$ interquartile range & \\
$\mathrm{P}_{\text {Emax }}=$ maximum inspiratory pressure & \\
\hline
\end{tabular}

relations between blood gas parameters and $\Delta \mathrm{P}_{0.1} / \Delta \mathrm{P}_{\mathrm{ETCO}_{2}}$ are expressed in terms of Pearson or Spearman coefficient when appropriate.

\section{Results}

Baseline demographics, $\mathrm{P}_{\mathrm{ETCO}_{2}}$, and $\Delta \mathrm{P}_{0.1} / \Delta \mathrm{P}_{\mathrm{ETCO}_{2}}$ slope values are summarized in Tables 1 and 2 . There were no significant differences in terms of age, sex, weight, height and $\mathrm{P}_{\mathrm{ETCO}}$ as well as body mass index between groups (see Table 1). Compared with controls (see Table 1), $\Delta \mathrm{P}_{0.1} / \Delta \mathrm{P}_{\mathrm{ETCO}_{2}}$ slope was lower (median 0.050 [interquartile range $0.027-0.118$ ] vs 0.183 [0.153-0.233], $P=.001$ ) in the late-onset Pompe disease group (Fig. 1). 


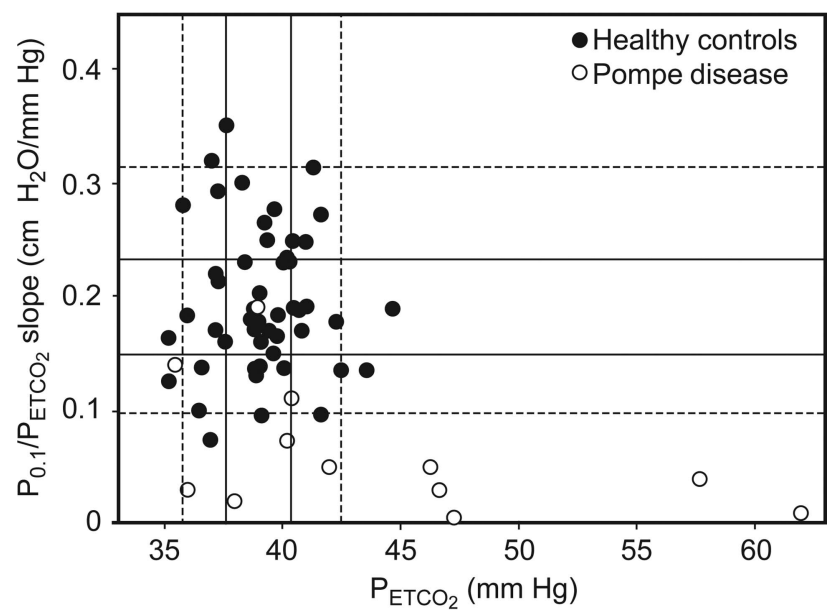

Fig. 1. Relationship between the $\Delta \mathrm{P}_{0.1}$ /end-tidal $\mathrm{CO}_{2}$ $\left(\Delta \mathrm{P}_{0.1} / \Delta \mathrm{P}_{\mathrm{ETCO}_{2}}\right)$ slope and the $\Delta \mathrm{P}_{\mathrm{ETCO}_{2}}$ in subjects with lateonset Pompe disease and healthy controls. Note that 11 lateonset Pompe disease subjects $(84.6 \%)$ showed a reduced hypercapnic drive response (slope below the $25 \%$ interquartile level), whereas $9(69.2 \%)$ had a slope below the $5 \%$ interquartile level.

Nine subjects with late-onset Pompe disease (69.2\%) had a blunted $\Delta \mathrm{P}_{0.1} / \Delta \mathrm{P}_{\mathrm{ETCO}_{2}}$ slope, and $5(38.5 \%)$ had chronic hypercapnia. Of note, 9 subjects $(69.2 \%)$ had an increased breath-holding time (see Table 2). ${ }^{9}$

Arterial blood gases were drawn in the late-onset Pompe disease group. Mean serum $\mathrm{pH}$ was 7.39 (range 7.32-7.44) in subjects with late-onset Pompe disease. Mean $\mathrm{P}_{\mathrm{CO}_{2}}$ was $43.8 \pm 8.2 \mathrm{~mm} \mathrm{Hg}$ (range 35.0-62.0) with 5 subjects presenting hypercapnia $(\geq 45 \mathrm{~mm} \mathrm{Hg})$, which is concordant with $\mathrm{P}_{\mathrm{ETCO}}$ values. Mean serum bicarbonate level was $25.9 \pm 2.9 \mathrm{mmol} / \mathrm{L}$ (range $22.0-$ 32.2 ), and 6 subjects presented a serum bicarbonate level $>26 \mathrm{mmol} / \mathrm{L}$.

As shown in Table 2, the percent-of-predicted FVC seated was $69.95 \%$ and decreased to $51 \%$ in the supine position. $\mathrm{P}_{\text {Imax }}$ values were above the lower limit of the normal range in 7 subjects (53.8\%), and the remaining 6 had values that were slightly lower than the lower limit of the normal range. Eight subjects $(61.5 \%)$ had $\mathrm{P}_{\text {Emax }}$ values above the lower limit of the normal range, and the rest had values that were slightly lower than the lower limit of the normal range.

In the late-onset Pompe disease group, there was a trend toward an inverse relationship between serum $\mathrm{P}_{\mathrm{CO}_{2}}$ levels and the $\Delta \mathrm{P}_{0.1} / \Delta \mathrm{P}_{\mathrm{ETCO}_{2}}$ slopes $(\mathrm{r}=0.47, P=.11)$, whereas no relationship was observed between $\mathrm{P}_{\text {Imax }}$ and $\mathrm{P}_{\mathrm{Emax}}$ and the $\Delta \mathrm{P}_{0.1} / \Delta \mathrm{P}_{\mathrm{ETCO}_{2}}$ slopes. There was no relationship between $\mathrm{P}_{\mathrm{ETCO}_{2}}$ and the slopes in the controls $(\mathrm{r}=0.008$, $P=.96)$. Figure 2 illustrates an example of a flat $\Delta \mathrm{P}_{0.1} / \Delta \mathrm{P}_{\mathrm{ETCO}_{2}}$ slope.

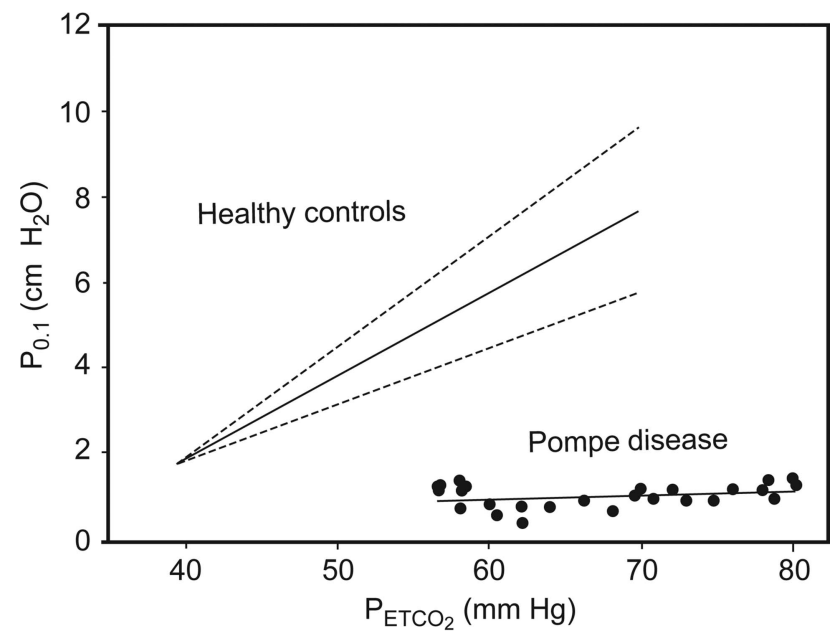

Fig. 2. The median $\Delta \mathrm{P}_{0.1} / \Delta \mathrm{P}_{\mathrm{ETCO}_{2}}$ slope value for healthy controls is shown along with their 25 th to 75 th percentiles (dotted lines). The group of points and its corresponding regression line depict a flat $\mathrm{CO}_{2}$ response of a subject with late-onset Pompe disease.

\section{Discussion}

In the present study, we found a blunted hypercapnic drive response in subjects with late-onset Pompe disease. The degree of hypercapnia found in these individuals seemed disproportionate to their respiratory muscle weakness. There was a trend toward an inverse relationship between the levels of serum $\mathrm{P}_{\mathrm{CO}_{2}}$ and the $\Delta \mathrm{P}_{0.1} / \Delta \mathrm{P}_{\mathrm{ETCO}_{2}}$ slope in these subjects, whereas there was no association between the hypercapnic drive response and the degree of respiratory muscle weakness in these individuals. The latter findings may reflect 2 different pathophysiological mechanisms that can affect respiratory status in a given patient. Thus, respiratory muscle weakness is only partly responsible for the respiratory deterioration witnessed in subjects with late-onset Pompe disease. Evaluation of the respiratory drive response in patients with neuromuscular disorders, such as late-onset Pompe disease, can be difficult in the presence of extreme respiratory muscle weakness and alterations of lung mechanics. Central drive is diminished in some patients with neuromuscular disease but not in the majority of cases. Before 1975, central breathing response was based on the ventilatory response, the latter being a parameter influenced by respiratory system resistance and compliance, and respiratory muscle weakness, which may cause variations in ventilation that do not reflect variations in the activity of the respiratory centers. ${ }^{5}$ Since then, determination of $\mathrm{P}_{0.1}$ has allowed the clinical assessment of central chemosensitivity. ${ }^{5,6,10}$ According to Holle et al, ${ }^{11}$ respiratory muscle weakness does not affect the $\mathrm{P}_{0.1}$ response to hypercapnia, as evidenced by the absence of changes of the $\mathrm{P}_{0.1} / \mathrm{P}_{\mathrm{CO}_{2}}$ slope with various degrees of inspiratory muscle weakness (up to $23 \pm 1 \%$ ). In 
addition, mild to moderate generalized respiratory muscle weakness in healthy subjects due to pharmacologic skeletal muscle paralysis does not affect ventilatory and mouth occlusion pressure response to hypercapnia. In a similar situation, in the presence of generalized respiratory muscle weakness, as observed in subjects with neuromuscular disorders, ventilatory response can be affected, but the mouth occlusion pressure response to $\mathrm{CO}_{2}$ remains intact. ${ }^{10,12-15}$ In our study, none of the subjects had muscle weakness comparable with Holle et al. ${ }^{11}$ Furthermore, we did not find a relationship between $\mathrm{P}_{\text {Imax }}$ percentage and $\Delta \mathrm{P}_{0.1} / \Delta \mathrm{P}_{\mathrm{ETCO}_{2}}$ slope values $(\mathrm{r}=0.550, P=.052)$.

Respiratory muscle weakness alone is sufficient to account for hypercapnia when respiratory muscle strength is $<30 \%$ of normal. A reduction of FVC below 55\% of predicted in patients with neuromuscular diseases is likely to be associated with hypercapnia. If, however, $\mathrm{CO}_{2}$ retention takes place with a FVC above this level or with respiratory muscle strength $>30 \%$ compared to normal values, coexisting lung disease and/or abnormality of ventilatory control may be present and are probably also contributing factors. ${ }^{16,17}$ These observations underscore the large reserve capacity of the respiratory system, which may, in turn, mask involvement of the respiratory muscles until late in the course of neuromuscular disease.

Consequently, prior studies focusing on the hypercapnic respiratory drive response in subjects with neuromuscular disorders have reported conflicting results. ${ }^{18}$ Some investigators have reported a normal hypercapnic respiratory drive response in subjects with neuromuscular disorders ${ }^{10,19}$; however, they only included normocapnic subjects. Others evaluated breathing control by measuring the hypercapnic ventilatory drive, ${ }^{14,20}$ a parameter affected by respiratory muscles weakness and impaired lung mechanics. Recently published data from our group demonstrated a flat hypercapnic drive response in subjects with myotonic dystrophy (Steinert disease) and chronic hypercapnia. ${ }^{3}$ Of note, in both studies, we found a prolonged breathholding time, which also suggests the presence of a blunted respiratory drive.

The fall in FVC in the recumbent position was present in 3 of 13 cases (23\%). In Pompe disease, in contrast with other neuromuscular disorders, there is early diaphragmatic involvement, which may help orient diagnosis. A decrease in FVC of $30-50 \%$ when the patient is supine supports the diagnosis of bilateral diaphragmatic paralysis, whereas a decrease in FVC of $10-30 \%$ when the patient is seated may be seen with mild diaphragmatic weakness or unilateral diaphragmatic paralysis. When there is little or no reduction in supine vital capacity, the presence of clinically important diaphragmatic weakness is unlikely. The mechanism related to the reduction in supine FVC is the cephalic displacement of abdominal contents in concert with ineffective activity of the accessory inspiratory mus- cles. Regarding the relationship between ventilatory control and hypercapnia, a chicken and egg question then becomes important: Is $\mathrm{CO}_{2}$ retention secondary to an underlying ventilatory control abnormality in these patients, or is the diminution in ventilatory sensitivity merely secondary to chronic $\mathrm{CO}_{2}$ retention?

Patients with chronic compensated respiratory acidosis have higher levels of plasma (as well as cerebrospinal fluid) bicarbonate because of bicarbonate retention by the kidneys. Therefore, for any increment in $\mathrm{P}_{\mathrm{CO}_{2}}$, the effect on $\mathrm{pH}$ at the medullary chemoreceptor is attenuated by the increased buffering capacity available. ${ }^{21}$ The brain- $\mathrm{CO}_{2}$ buffering capacity increases in respiratory acidosis and decreases in respiratory alkalosis. ${ }^{22}$ The central drive is influenced by the acid/base status. In chronic respiratory acidosis, the central response to acute $\mathrm{CO}_{2}$ inhalation is reduced. This finding has been described in subjects with chronic obstructive pulmonary disease and hypercapnia. ${ }^{23}$

In normal subjects, the slope of the $\mathrm{CO}_{2}$ response line during steady-state $\mathrm{CO}_{2}$ inhalation was unaffected by chronic alkalosis and acidosis. ${ }^{24-26}$ Using the rebreathing technique, there was no significant change in intercept in acidosis and alkalosis, but the slope $\left(\Delta \dot{\mathrm{V}}_{\mathrm{E}} / \Delta \mathrm{P}_{\mathrm{CO}_{2}}\right)$ varied from the control values. The mean slope value during alkalosis $\left(\mathrm{pH} 7.44 \pm 0.02\right.$, plasma $\mathrm{HCO}_{3}^{-} 28.5 \pm 3.0$ $\mathrm{mmol} / \mathrm{L}$ ) was 0.6 times the average baseline. ${ }^{26}$ To our knowledge, a flat $\Delta \mathrm{P}_{0.1} / \Delta \mathrm{P}_{\mathrm{CO}_{2}}$ slope response has not been described in the setting of metabolic alkalosis. Thus, a combination of factors can lead to abnormal patterns of breathing and hypoventilation in these disorders; no single pathophysiologic mechanism can explain all of the abnormalities. Clinically, it is important to appreciate the prevalence of ventilatory control disorders and include appropriate evaluations when assessing patients with neuromuscular diseases and offering therapeutic options. ${ }^{19}$

In our study, $69.2 \%$ of subjects had a flat $\mathrm{CO}_{2}$ response, which could be attributed to alterations in the acid/base state. However, 4 of 9 subjects with a flat $\mathrm{CO}_{2}$ response were normocapnic. Therefore, it appears that hypercapnia may not be the main factor responsible for a flat $\mathrm{CO}_{2}$ response.

To our knowledge, this is the first study evaluating the control of breathing using the $\mathrm{P}_{0.1}$ response to $\mathrm{CO}_{2}$ in subjects with late-onset Pompe disease. The potential clinical interest in evaluating the $\mathrm{CO}_{2}$ response test in these patients could be the ability to improve risk stratification during a concomitant unrelated medical problem or before an invasive diagnostic or therapeutic procedure. The presence of a blunted respiratory drive, regardless of the degree of respiratory muscle compromise, may call for closer monitoring in these individuals to limit pulmonary complications.

Although our study included a small number of subjects with late-onset Pompe disease, our findings appear con- 


\section{Blunted Respiratory Drive in Pompe Disease}

clusive, since the majority (84.6\%) of subjects showed a reduced hypercapnic drive response (a slope below the $25 \%$ interquartile level) despite mild impairment of respiratory muscles and lung mechanics and normal bicarbonate levels. Mean serum bicarbonate level was $25.9 \pm 2.9$ $\mathrm{mmol} / \mathrm{L}$ (range 22.0-32.2), and only 5 subjects had bicarbonate $>26 \mathrm{mmol} / \mathrm{L}$. A larger sample size may confirm our findings and help identify factors that may influence hypercapnic respiratory drive. We have not performed autonomic function tests to evaluate the integrity of the autonomic nervous system. In that sense, several studies have found glycogen deposition in the brain in subjects with the infantile form of Pompe disease, causing overt autonomic neuropathy and other neurological derangements, ${ }^{27-29}$ whereas no data are available so far in subjects with lateonset Pompe disease. ${ }^{30}$

\section{Conclusions}

Subjects with late-onset Pompe disease had a reduced hypercapnic drive that may contribute to carbon dioxide retention. The clinical repercussion of this phenomenon in this subject subset deserves further investigation.

\section{REFERENCES}

1. Di Rocco M, Buzzi D, Tarò M. Glycogen storage disease type II: clinical overview. Acta Myol 2007;26(1):42-44.

2. ACMG Work Group on Management of Pompe Disease, Kishnani PS, Steiner RD, Bali D, Berger K, Byrne BJ, et al. Pompe disease diagnosis and management guideline. Genet Med 2006;8(5):267288.

3. Aruj PK, Monteiro SG, De Vito EL. [Analysis of factors associated with chronic hypercapnia in patients with myotonic dystrophy]. Medicina 2013;73(6):529-534.

4. Raurich JM, Rialp G, Llompart-Pou JA, Ayestarán I, Pérez-Bárcena J, Ibáñez J. Respiratory $\mathrm{CO}(2)$ response in acute cervical spinal cord injury $(\mathrm{CO}(2)$ response in spinal cord injury). Spinal cord 2014; 52(1):39-43

5. Whitelaw WA, Derenne JP, Milic-Emili J. Occlusion pressure as a measure of respiratory center output in conscious man. Respir Physiol 1975;23(2):181-199.

6. Whitelaw WA, Derenne JP. Airway occlusion pressure. J Appl Physiol 1993;74(4):1475-1483.

7. Evans JA, Whitelaw WA. The assessment of maximal respiratory mouth pressures in adults. Respir Care 2009;54(10):1348-1359.

8. Learn \& Master ACLS. ACLS-algorithms.com. Quantitative Waveform Capnography. https://acls-algorithms.com/waveform-capnography/

9. Mitrouska I, Tsoumakidou M, Prinianakis G, Milic-Emili J, Siafakas NM. Effect of voluntary respiratory efforts on breath-holding time. Respir Physiol Neurobiol 2007;157(2):290-294.

10. Bégin R, Bureau MA, Lupien L, Lemieux B. Control and modulation of respiration in Steinert's myotonic dystrophy. Am Rev Respir Dis 1980;121(2):281-289.
11. Holle RH, Schoene RB, Pavlin EJ. Effect of respiratory muscle weakness on P0.1 induced by partial curarization. J Appl Physiol 1984;57(4):1150-1157.

12. Baydur A. Respiratory muscle strength and control of ventilation in patients with neuromuscular disease. Chest 1991;99(2):330-338.

13. Bégin R, Bureau MA, Lupien L, Lemieux B. Control of breathing in Duchenne's muscular dystrophy. Am J Med 1980;69(2):227-234

14. Carroll JE, Zwillich CW, Weil JV. Ventilatory response in myotonic dystrophy. Neurology 1977;27(12):1125-1128.

15. Tantucci C, Massucci M, Piperno R, Betti L, Grassi V, Sorbini CA. Control of breathing and respiratory muscle strength in patients with multiple sclerosis. Chest 1994;105(4):1163-1170.

16. Matecki S, Petrof BJ. Respiratory consequences of neuromuscular disease. In: Hamid Q, Martin J, editors. Physiologic basis of respiratory disease. Hamilton, Ontario, Canada: BC Decker; 2005:319329.

17. Braun NM, Arora NS, Rochester DF. Respiratory muscle and pulmonary function in polymyositis and other proximal myopathies. Thorax 1983;38(8):616-623.

18. Borel CO, Teitelbaum JS, Hanley DF. Ventilatory drive and carbon dioxide response in ventilatory failure due to myasthenia gravis and Guillain-Barre syndrome. Crit Care Med 1993;21(11):1717-1726.

19. Johnson DC, Kazemi H. Central control of ventilation in neuromuscular disease. Clin Chest Med 1994;15(4):607-617.

20. Carroll JE, Zwillich C, Weil JV, Brooke MH. Depressed ventilatory response in oculocraniosomatic neuromuscular disease. Neurology 1976;26(2):140-146

21. Kazemi H. Cerebrospinal fluid and the control of ventilation. In: Crystal RG, West JB, Weibel ER, Barnes PJ, editors. The lung: scientific foundations, 2nd edition. Philadelphia: Lippincott-Raven Publishers; 1997:1777.

22. Kazemi H, Shore NS, Shih VE, Shannon DC. Brain organic buffers in respiratory acidosis and alkalosis. J Appl Physiol 1973;34(4):478482.

23. Park SS. Respiratory control in chronic obstructive pulmonary diseases. Clin Chest Med 1980;1(1):73-84.

24. Irsigler GB, Stafford MJ, Severinghaus JW. Relationship of CSF pH, $\mathrm{O}_{2}$, and $\mathrm{CO}_{2}$ responses in metabolic acidosis and alkalosis in humans. J Appl Physiol 1980;48(2):355-361.

25. Oren A, Whipp BJ, Wasserman K. Effects of chronic acid-base changes on the rebreathing hypercapnic ventilatory response in man. Respiration. 1991;58(3):181-185.

26. Linton RA, Poole-Wilson PA, Davies RJ, Cameron IR. A comparison of the ventilatory response to carbon dioxide by steady-state and rebreathing methods during metabolic acidosis and alkalosis. Clin Sci Mol Med 1973;45(2):239-249.

27. Fuller DD, ElMallah MK, Smith BK, Corti M, Lawson LA, Falk DJ, Byrne BJ. The respiratory neuromuscular system in Pompe disease. Respir Physiol Neurobiol 2013;189(2):241-249.

28. Falk DJ, Mah CS, Soustek MS, Lee KZ, Elmallah MK, Cloutier DA, et al. Intrapleural administration of AAV9 improves neural and cardiorespiratory function in Pompe disease. Mol Ther 2013;21(9):16611667.

29. Kishnani PS, Beckemeyer AA, Mendelsohn NJ. The new era of Pompe disease: advances in the detection, understanding of the phenotypic spectrum, pathophysiology, and management. Am J Med Genet C Semin Med Genet 2012;160C(1):1-7.

30. Wirsching A, Müller-Felber W, Schoser B. Are evoked potentials in patients with adult-onset Pompe disease indicative of clinically relevant central nervous system involvement? J Clin Neurophysiol 2014; 31(4):362-366. 